\title{
La dinámica social de las orientaciones de desarrollo en América Latina*
}

\section{Social dynamic of the development guidelines in Latin America}

François Houtart

Sacerdote católico y sociólogo marxista belga, es el fundador del Centro Tricontinental (CETRI) que funciona en la Universidad Católica de Lovaina y de la revista "Alternatives Sud", Bélgica. Figura reconocida del movimiento altermundista y pensador influyente de la teología de la liberación, es autor de más de 50 libros entre los que se destacan El cambio social en América Latina (1961), Sociología de la religión (1992), Deslegitimar el capitalismo, reconstruir la esperanza (2009), entre otros. Actualmente se desempeńa como docente e investigador en el IAEN. Contacto: Francois.houtart@iaen.edu.ec.

Artículo de reflexión

Fecha de recepción: noviembre 6 de 2015 • Fecha de aprobación: noviembre 10 de 2015

\section{RESUMEN}

Este trabajo busca comprender las transformaciones que se han operado en el modelo de acumulación capitalista en América Latina en las últimas décadas, en particular mediante la transición de un modelo de índole neoliberal a otro que, si bien no ha roto con las características esenciales de acumulación del modelo anterior, busca articular procesos de desarrollo económico con marcadas transformaciones estructurales sobre la base de políticas sociales de carácter redistributivo. Frente a las contradicciones internas del modelo, esta reflexión ofrece también itinerarios para buscar una opción postcapitalista, centrada en la búsqueda del bien común.

* Texto de la conferencia presentado en el marco de los 50 años de la Facultad de Sociología de la Universidad Santo Tomas, Bogotá, el 30 de octubre de 2015. Con base en el texto escrito de la ponencia entregada por el autor, este trabajo ha sido editado por François-Xavier Tinel, docente-investigador de la Maestría en Planeación para el Desarrollo de la Facultad de Sociología de la Universidad Santo Tomás y líder del grupo de investigación "Conflictos sociales, género y territorios". Contacto: francoistinel@usantotomas.edu.co. 
Palabras clave: desarrollo, acumulación capitalista, neoliberalismo, post-neoliberalismo, América Latina.

\begin{abstract}
This paper seeks to understand the transformations that have occurred in the model of capitalist accumulation in Latin America in recent decades, particularly through the transition from a model of neoliberal kind to another, that even if it has not broken with the essential characteristics of accumulation from the previous model seeks to articulate processes of economic development with marked structural transformations based on redistributive social policies. Faced with the internal contradictions of the model, this reflection also offers itineraries to search for a post-capitalist option, focusing on the common good.
\end{abstract}

Keywords: Development, capitalist accumulation, neoliberalism, post-neoliberalism, Latin America.

América latina ofrece un rostro atípico en relación con la experiencia del neoliberalismo al ser el único continente en el mundo en el que varios países lograron superar este modelo. No obstante, las recientes crisis que han enfrentado las economías latinoamericanas así como ciertas dificultades políticas ponen en peligro lo que se ha denominado como el "modelo postneoliberal" por razones comunes, como la caída de los precios de las commodities, y particulares a cada uno de ellos.

El método weberiano de los "modelos-tipos" servirá de marco analítico para comprender las orientaciones principales de cada uno de ellos: el neoliberal, el postneoliberal y el postcapitalista. A pesar de las divergencias histórico-estructurales propias a la realidad de cada país, existen rasgos compartidos que permiten reconocer patrones comunes en torno a las orientaciones de desarrollo en América Latina. 


\section{LA ORIENTACIÓN NEOLIBERAL}

\section{Características generales}

El neoliberalismo es una fase del capitalismo que, para favorecer el proceso de acumulación, acentúa la privatización de la producción de los bienes y servicios, promueve la liberalización de los intercambios y reduce el papel del Estado a sus funciones regalianas, a saber, de protección de la propiedad privada y de seguridad.

Es importante recordar que la lógica del capitalismo se articula en torno al principio de acumulación del capital como el motor del desarrollo económico; los otros factores de orden social, político y cultural no son más que corolarios de dicho fin y deben contribuir a garantizar la estabilidad del sistema. La fuerza de este principio radica en el carácter universal de la ley del mercado, aplicable en lugares heterogéneos así como en sectores sociales diversos de tal manera que la economía logre emerger como un elemento desenraizado de lo social que busca aplicar las reglas del liberalismo económico a todo el conjunto societal, convirtiendo a los seres humanos y la naturaleza en meras mercancías (Polanyi, 2003).

Asimismo, es de resaltar la capacidad de transformación del capitalismo; en efecto, este último transitó de una fase industrial a otra de tipo financiero. Si bien en la primera las lógicas de la acumulación estaban ligadas a los medios físicos de producción, en la segunda, la acumulación de capital se genera en base al principio de especulación, lo cual significa que el valor que se genera es puramente ficticio (Gorz, 2009). Así, el hecho de que el capital financiero gobierne la economía mundial ha provocado mayor inestabilidad del sistema, al ser desregulado y descontrolado, funcionando a la manera de un casino (Strange, 1999). Por ejemplo, Robert Reich, antiguo secretario del trabajo del presidente Clinton, escribió para ilustrar este fenómeno, en un libro sobre la Globalización: "Siemens es un banco que también fabrica aparatos electrodomésticos". 


\section{Las consecuencias estructurales para las sociedades latinoamericanas}

Las dos estrategias del capitalismo para garantizar o acelerar el proceso de acumulación son, por un lado, la concentración de los recursos y de las decisiones y, por otro, la ignorancia de las externalidades, es decir lo que no entra en el cálculo del mercado, en particular los dańos ecológicos y sociales. La concentración se realiza en tres ámbitos precisos. En primer lugar, en lo referente a la tierra, mediante un verdadero proceso de contra-reforma agraria, en manos de grandes productores o de empresas multinacionales, se pretender fomentar el desarrollo de los monocultivos de exportación; en segundo lugar, la lógica del capital se amplía en varios sectores como las finanzas, los hidrocarburos, la minería y la agricultura. Finalmente, en lo que tiene que ver con el aumento de la riqueza, se evidencia un aumento substancial del número y tamaño de las grandes fortunas. El índice de Gini que mide la desigualdad en la repartición de la riqueza entre los ingresos de los más ricos y los más pobres, ayuda a dar cuenta de la forma en que se distribuyen las riquezas así como de las crecientes brechas.

La ignorancia de las externalidades no pagadas por el capital, sino por las comunidades, los pueblos o los individuos, incide directamente en el ambiente natural y en la vida colectiva. Lo anterior trae a colación una serie de consecuencias muy graves y a veces irreversibles como la destrucción de la selva amazónica, la contaminación de los suelos, de las aguas, del aire, la desaparición de ecosistemas y de la biodiversidad o aún la pérdida de la soberanía alimentaria. De igual manera, el desplazamiento de poblaciones, las migraciones hacia las grandes ciudades o al extranjero, la desertificación social del campo, son otras de las consecuencias de la ignorancia de las externalidades.

En efecto, dicha problemática puede ilustrarse a través de varios ejemplos. Los agrocombustibles son presentados como energía verde y como una solución factible a corto plazo frente al agotamiento de las energías fósiles; sin embargo, en sus procesos de producción, dañan considerablemente al medio ambiente y provocan la expulsión de millones de campesinos de sus tierras. Por ejemplo, en Colombia, la extensión de los monocultivos de palma de aceite en el norte del departamento del Chocó se dio de manera concomitante con la entrada de los paramilitares en la zona. Igualmente, 
se puede observar la concentración de las tierras, la destrucción de los bosques y de la biodiversidad así como la utilización masiva de productos químicos y el uso de energía fósil para procesarlos. Además se suma el hecho de las malas condiciones de trabajo y el problema de la sumisión de los pequeños campesinos por los contratos que crea una total dependencia del capital. Cabe añadir que la producción de agrocombustibles, igual que la de todos los otros monocultivos, afecta gravemente la salud de los trabajadores y de las poblaciones vecinas. Finalmente, estos contribuyen a reforzar la división internacional del trabajo y la reprimarización de la economía latinoamericana ${ }^{1}$.

Otro ejemplo de interés es el del extractivismo (forma capitalista de la extracción) que está afectando todos los continentes del Sur. A diferencia de la extracción basada sobre el valor de uso, es decir que tiene una verdadera utilidad para los seres humanos y corresponde a prácticas socioculturales y económicas tradicionales, el extractivismo corresponde al predominio del valor de cambio y se introdujo en América Latina con el capitalismo mercantil y la colonización. Para el capitalismo, existe un solo valor capaz de contribuir al proceso de acumulación: el valor de cambio (todo debe transformarse en mercancía para ser la base de la ganancia ${ }^{2}$ ); por tanto, el valor de uso debe ser sometido al primero. No es azar que el lenguaje económico haga referencia al medio ambiente como una serie de recursos naturales que pueden explotarse y no hable en términos de riquezas naturales. Frente al problema del agotamiento de las riquezas naturales, se implementa cada vez más el uso de nuevas tecnologías (fragmentación, minas a cielo abierto) que causan daños ecológicos considerables y que, en muchos casos, significan una agresión territorial a pueblos indígenas.

Finalmente, un tercer ejemplo es el de la selva amazónica. Según la lógica neoliberal, se trata de un recurso natural que debe ser explotado según el principio del mercado

1 Para profundizar la discusión sobre el tema ver: Houtart, Sánchez Garzoli, Birkenes, Colectivo Agrario Abya Yala, Coordinadora Nacional Campesina, León Moncayo y Comisión de Justicia y Paz (2014). Agrocombustibles. Falsa solución global y destrucción local en Colombia. Bogotá: Ediciones desde abajo.

2 Polanyi (2003). reconoce en la voluntad de hacer del trabajo, el dinero y la naturaleza unas meras mercancías el corazón del proyecto utópico del liberalismo económico de crear un mercado autoregulado. Señala que estas mercancías son ficticias porque no se pueden separar del ámbito de las relaciones políticas, simbólicas, sociales, culturales y religiosas en las que se expresan. 
sin preocuparse por las externalidades a menos que afecten la tasa de ganancia. De acuerdo con lo anterior, no existe ningún límite a la explotación petrolera, minera, de gas o de madera, tampoco al monocultivo o a los megaproyectos de hidroenergía. Por tanto, frente a las crecientes críticas ambientales sobre el carácter depredador del capitalismo, en particular en su relación con la naturaleza, el discurso del desarrollo sustentable aparece como el aparato ideológico del capitalismo global a través del cual se pueden legitimar las lógicas de acumulación de capital; es así que se reemplaza el término "explotación" por "aprovechamiento racional" de los recursos naturales, en el sentido en que no se debe comprometer el acceso a estos recursos para las futuras generaciones.

\section{Otras consecuencias sociales y culturales}

Los países neoliberales estiman que la lucha contra la pobreza es importante porque amplía la base del mercado. En el conjunto de América Latina, se han desarrollado una serie de programas en esta dirección con resultados alentadores y que están articulados con las recomendaciones del Banco Mundial y los planteamientos de los Objetivos de Desarrollo del Milenio de las Naciones Unidas, los cuales pasaron a ser ahora los Objetivos del Desarrollo Sostenible hasta el año 2030.

De igual manera, el neoliberalismo sustenta que la educación debe estar al servicio del mercado, en particular la educación superior, con preferencia para el sector privado. Es en este sentido que se orientan las reformas educacionales. También en el ámbito de la salud, el Estado debe disminuir su intervención para privilegiar el sector privado; lo mismo es válido para el resto de los servicios públicos que solamente contribuyen a la acumulación del capital cuando están privatizados. Por ende, se reduce así al mínimo el espacio del bien común.

Paralelamente, los tratados de libre comercio refuerzan la división internacional del trabajo; tienden a favorecer el sector agroexportador en detrimento de la agricultura tradicional y provocan una pérdida progresiva tanto de la soberanía alimentaria como de los derechos de propiedad intelectual que terminan siendo monopolizados por las empresas multinacionales. Con grados diferentes, países como México, 
Guatemala, Honduras, Panamá, Colombia, Perú, Paraguay y Chile se ven afectados estructuralmente por las condiciones impuestas por el capitalismo neoliberal.

En suma, esta orientación de desarrollo entra en la lógica de la absorción de la plusvalía, por un lado, gracias a mecanismos reales como la proletarización y, por otro, a través de mecanismos formales como el de la deuda externa, las políticas monetarias, la concentración del capital y, finalmente, el despojo, es decir mediante la expulsión de la población de sus tierras. Lo anterior resulta de la aplicación en el continente de una lucha de clases a escala mundial donde el capital con sus instituciones legales (FMI, Banco Mundial, BID, OMC) e ilegales (paraísos fiscales) actúa para mantener y ampliar su proceso de acumulación.

\section{LA ORIENTACIÓN POSTNEOLIBERAL DE MODERNIZACIÓN}

Desde hace aproximadamente una década, América Latina ha operado una transformación política que se manifiesta en la adopción de otra orientación de desarrollo, con las siguientes particularidades: el retorno del Estado, la modernización de la sociedad, un nuevo tipo de capitalismo y cierto giro social en su lucha contra la pobreza y la desigualdad.

\section{El retorno del Estado}

La característica principal de una fase postneoliberal del capitalismo es el retorno del Estado como regulador de la economía y redistribuidor de la riqueza pese a que no exista una transformación en el modelo de acumulación. De alguna forma, esto permite hacer convivir el proceso continuo de acumulación capitalista con preocupaciones sociales. Es la era de un capitalismo social, también calificado de "verde", que no cambia la lógica fundamental del sistema económico (maximización de la ganancia e ignorancia de las externalidades), sino que alivia, en cierta medida y según los países, las consecuencias más penosas. Así, se realiza mediante políticas económicas (renegociación de la deuda externa en Ecuador) o sociales (medidas asistencialistas de lucha contra la pobreza que crean clientes pero no actores sociales 
nuevos) y busca proveer un mejor acceso a los servicios públicos en los ámbitos de la salud y la educación.

\section{Modernización de la sociedad}

Por modernización de la sociedad nos referimos al proceso que busca tanto hacer salir un país de un "retraso" económico, social y cultural que lo impide competir en el mercado mundial como edificar una sociedad de bienestar social que sitúe la nación en una escala aceptable dentro del panorama internacional. La modernidad adopta implícitamente y de manera acrítica la idea de un progreso lineal sobre un planeta inagotable, es decir un concepto desviado por la lógica del capitalismo como lo reconocía Echevarría (1999).

\section{Un capitalismo moderno}

El nuevo capitalismo o capitalismo moderno acepta la lucha contra la pobreza porque contribuye a ampliar la masa de consumidores, lo cual es benéfico, a medio o largo plazo, para anchar la demanda en el mercado. Desde esta perspectiva, tener un trabajo formal así como un seguro social son garantías para la estabilidad de la mano de obra y así para garantizar la perennidad del mercado. A su vez, el pago de contribuciones sociales ya no es visto como un freno a las libertades individuales sino más bien como un medio para que el Estado sea el garante de mayores niveles de estabilidad política; lo anterior constituye un prerrequisito importante para incentivar la inversión y favorecer los procesos de acumulación.

En este sentido, podemos afirmar que el capitalismo moderno toma sus distancias frente al capitalismo oligárquico tradicional. Incluso una parte de sus protagonistas hacen parte del sistema político nuevo; otros hacen parte de la oposición cuando piensan que este último no asegura una tasa de ganancia suficiente. Sin embargo, este capitalismo moderno depende mucho de las vinculaciones con el capital monopolista exterior; por ello, cuando ocurren crisis en el proceso de acumulación, los logros sociales alcanzados terminan siendo las "primeras víctimas” como lo fue en Brasil. 
Este capitalismo moderno se caracteriza también por su capacidad para articular el capital local con el internacional como lo refleja el caso argentino de los monocultivos de soja. A su vez, las normatividades nacionales constituyen un marco legal que protege y cobija los procesos de acumulación capitalista como lo ejemplifica el código forestal en Brasil que está redactado a favor de la "agricultura moderna", es decir de los monocultivos (soja, palma, caña). De igual manera, en Bolivia, existe un acuerdo que vincula el Gobierno con los propietarios terrenos de la Media Luna para extender la frontera agraria de un millón de hectáreas. También, en Ecuador, la nueva matriz productiva favorece los monocultivos de exportación a pesar de sus consecuencias ambientales y sociales. Lo mismo ocurre en Nicaragua donde el capital agrario tradicional se transforma en moderno y entran en escena los nuevos sectores de acumulación (comercio internacional, etc.).

Al mismo tiempo, el petróleo, el gas y la minería se desarrollan como fuentes de financiación de las políticas sociales, pero hacen también parte del extractivismo mundial (forma capitalista de la extracción) y dan un nuevo espacio a empresas multinacionales. De manera general, se puede observar que el sector financiero, el gran comercio, las comunicaciones, los intermediarios con sus nuevos inversores (China, Qatar, Arabia Saudita), conocen tasas elevadas de ganancias. Así, la desindustrialización relativa, incluso de un país como Brasil, debe comprenderse como el resultado de la reprimarización de las economías latinoamericanas, impuesta por el capitalismo como sistema-mundo y apoyado por las instituciones financiarías internacionales.

\section{Las políticas sociales}

El retorno del Estado en varios sectores de los "comunes" se traduce por inversiones públicas importantes: infraestructuras (Ecuador), educación y salud (todos), lucha contra la pobreza, a través de medidas compensatorias (Brasil, Ecuador, Bolivia), ampliación del seguro social, etc. En tanto se trata de modernizar una sociedad, la iniciativa viene esencialmente del poder político que, por razones de eficiencia, tiende a centralizarse, dando al ejecutivo un lugar privilegiado, dejando poco espacio a la participación y concibiendo la comunicación como una explicación de lo que se ha hecho. Es así que los valores de la excelencia y de la competencia resultan ser 
centrales, también en la reforma del sistema educacional (en el Ecuador: escuelas del milenio y las superuniversidades). De esta forma, la agricultura familiar campesina y la agricultura indígena se ven marginalizadas porque son consideradas como poco productivas (en todos los países). Por ende, pese a los avances constitucionales logrados en naciones como Ecuador y Bolivia en términos de reconocimiento de la diversidad cultural, las llamadas minorías étnicas siguen siendo marginadas por el sistema económico y tienen una voz diminuta en el sistema político. Con el fin de tener una lectura global del contexto, vale la pena señalar también que la clase media ha tenido un aumento importante (representa entre el $30 \%$ y el $50 \%$ de la población según los países), y que su consumo influye mucho en la balance comercial.

Varias son las versiones de este modelo en América Latina. En Brasil, Lula, sindicalista de la metalurgia, siempre ha tenido dos valores claves: la eficacia y la justicia social. La eficacia en el dominio económico es el capitalismo y la justicia busca la redistribución de una parte del producto social a los más pobres. En Ecuador, la nueva matriz productiva, que quiere, con razón, favorecer la producción nacional y reducir las exportaciones, reemplaza progresivamente el concepto inicial del "buen vivir".

Empero, con la crisis que afecta al continente se asiste a un agotamiento del modelo postneoliberal como lo reconoció la presidente de Brasil Dilma Rousself en su discurso en la Asamblea General de las Naciones Unidas en septiembre de 2015. Lo anterior se materializa claramente en Brasil por el retorno a políticas que satisfacen los mercados. El peligro de una evolución semejante existe para los otros países postneoliberales de América, es decir Argentina, Uruguay, Nicaragua, Venezuela, Ecuador y Bolivia. Cabe anotar que, en el caso ecuatoriano, la existencia de reservas importantes puede atrasar un poco el proceso. Así, el ejemplo de Grecia muestra que dentro de una lógica que no ha salido del modelo de acumulación capitalista, no se presentan muchas alternativas a las políticas de austeridad; estas hacen pagar a los más vulnerables los efectos de la crisis financiera y económica y permiten al capital reanudar un ciclo de acumulación, en particular con el aporte de inversiones exteriores y de nuevos préstamos.

No se trata de negar los logros de los países postneoliberales, sino de saber cómo van a reaccionar frente a una crisis mundial que afecta al proyecto: regresar al 
neoliberalismo o iniciar transiciones hacia una orientación postcapitalista constituye un dilema importante.

\section{HACIA UNA OPCIÓN POSTCAPITALISTA}

Esta orientación solo se puede proponer como una meta porque no tiene aún una realización política a pesar de que existan muchas iniciativas económicas, sociales y culturales que van en este sentido. A continuación, nos referiremos a ciertos ensayos que se han realizado en América Latina como a sus principios y aplicaciones posibles.

\section{Los ensayos}

La Revolución cubana ha sido el resultado de la voluntad de constituir una sociedad postcapitalista. El proceso de la revolución cubana ha enfrentado una serie de dificultades, obstáculos y limitaciones; por una parte, dado el aislamiento en un océano capitalista ( $y$ con un embargo) y, por otra parte, por la arquitectura misma del socialismo del siglo XX, es decir de una concepción acrítica de la modernidad, una división del trabajo interna al mundo socialista (monocultivo del azúcar dentro del COMECOM), un socialismo de guerra así como últimamente una serie de ensayos para salvar los logros socialistas frente a las nuevas relaciones económicas y políticas de un mundo dominado por la ley del mercado. Sin embargo muchas enseñanzas pueden servir de base para la reflexión.

La ALBA (Alianza Bolivariana para los Pueblos de Nuestra América) se construyó sobre una base de teoría económica, opuesta al capitalismo: no sobre la competencia, sino sobre los principios de la complementariedad y la solidaridad. Varias aplicaciones concretas resultan de estas primicias. En el plano económico, Petrocaribe ofrece un precio preferencial a los países no productores de petróleo; en el plano social, se puede resaltar la operación Milagros que consiste en una operación humanitaria con técnica médica cubana y apoyo económico venezolano que busca luchar contra la ceguera por cataratas; en lo cultural, TeleSur es una cadena televisiva multiestatal que transmite en señal libre y sin costo. Sin embargo, a escala del continente, la 
experiencia se queda relativamente marginal y muy vulnerable, dependiente en mayor parte de una Venezuela bolivariana.

\section{Los pasos de una transición posible}

Un paradigma postcapitalista de la vida colectiva sobre el planeta exige una redefinición de sus ejes fundamentales. En la relación con la naturaleza, se debe pasar de una concepción centrada en explotación a otra basada en el respeto, en la resignificación de la naturaleza como fuente de toda vida; acerca de la producción de la base material de la vida, se debe privilegiar el valor de uso sobre el valor de cambio; en el plano político, se debe buscar la generalización de los procesos democráticos en las instituciones sociales y políticas y en todas las relaciones sociales (incluido hombres-mujeres); finalmente, en lo cultural, se plantea el fin de la hegemonía de la cultura occidental para adoptar la interculturalidad.

Se podrían dar algunos ejemplos de transiciones hacia un postcapitalismo, que se llame Socialismo del siglo XXI, Buen Vivir, Bien Común de la Humanidad (Houtart, 2011) o como quieran, mientras exista una preocupación por el contenido del concepto.

\section{a. Transformar la relación con la naturaleza}

Se trata de realizar el paso del extractivismo (basado sobre el valor de cambio) a la extracción (basada sobre el valor de uso), implicando como primer elemento la aplicación de leyes sociales y ambientales más severas. A la par, se requiere tanto de una acción a escala de la integración continental porque un solo país no puede afrontar solo la fuerza de las multinacionales del sector como de una legislación internacional para evitar las "ventajas comparativas" de países que no respetan las normas sociales y ambientales.

Estas medidas propuestas anteriormente aplican también para los monocultivos de exportación. Así, frente a la destrucción de las selvas y bosques, una reforestación masiva con plantas y árboles nativos sería un punto de partida necesario y debería 
ser acompañado por la creación de condiciones favorables a la ampliación de la agricultura familiar campesina e indígena.

\section{b. Privilegiar el valor de uso}

La transición en este sector podría consistir en abolir los paraísos fiscales en la región y nacionalizar las principales instituciones financieras, realizar una reforma agraria integral y popular como lo plantea el programa del Movimiento Sin Tierra en Brasil, promover el mercado interno, los circuitos cortos y la soberanía alimentaria, luchar contra la reprimarización y promover la economía popular solidaria.

\section{c. Generalizar los procesos democráticos y la participación}

Se requiere que las políticas de lucha contra la pobreza estén centradas en la manera de producir más que en el aumento del consumo, construyendo actores sociales y no clientes (políticas de compensación). Lo anterior constituye una primera propuesta. También se considera urgente ampliar los mecanismos de participación en todos los sectores (economía, política, cultura, deporte, sindicatos, religiones, etc.). Un punto esencial será la descentralización de los Estados, desde abajo, la comunicación y el diálogo como formas de participación.

\section{d. Promover la interculturalidad}

Asegurar la participación de todas las culturas, los saberes, las espiritualidades a la construcción de un paradigma postcapitalista es un paso indispensable para la construcción de una ética adecuada, de un pensamiento crítico y de valores espirituales capaces de transformar lo cotidiano y de dar un sentido a la vida.

Muchos otros ejemplos de transición a una orientación postcapitalista podrían ser citados porque ya funcionan a pequeńa escala o son realizados por iniciativas y movimientos populares, en varias partes del mundo; ello comprueba que no se trata de una utopía en el sentido de ilusión. Entonces, la nueva etapa consistiría esencialmente en construir los nuevos actores políticos para la gestión del cambio esperado. 


\section{REFERENCIAS}

Echevarría, B. (1999). La modernidad de lo barroco. México: Ediciones Era.

Gorz, A. (2009). "La salida del capital ya ha empezado". Revista El Viejo Topo, (258259)2009, pp. 77-81.

Houtart, F. (2011). De los bienes comunes al 'bien común de la humanidad'. Bruselas: Fundación Rosa Luxemburgo

Houtart, F., Sánchez, G. G., Birkenes, A., Colectivo Agrario Abya Yala, Coordinadora Nacional Campesina, León Moncayo, H. \& Comisión de Justicia y Paz. (2014). Agrocombustibles. Falsa solución global y destrucción local en Colombia. Bogotá: Ediciones desde abajo.

Polanyi, K. (2003). La gran transformación. Los orígenes politicos y económicos de nuestro tiempo. México: FCE

Strange, S. (1999). Dinero loco: el descontrol del sistema financiero global. Barcelona. Paídos Ibérica. 